\title{
METODOLOGIA PARA RESGATE DE MATRIZES E ENRAIZAMENTO DE ESTACAS DE Eremanthus erythropappus
}

\author{
Lucas Amaral de Melo ${ }^{1}$, Antonio Claudio Davide², Luís Antônio Fonseca Teixeira ${ }^{3}$
}

(recebido: 15 de março de 2011; aceito: 29 de junho de 2012)

\begin{abstract}
RESUMO: Pelo importante papel ecológico que a espécie Eremanthus erythropappus (candeia) desempenha, aliado à crescente demanda pelos produtos obtidos dessa espécie, trabalhos vêm sendo feitos com o intuito de desenvolver sua silvicultura. Dentre os estudos com a espécie, é necessário iniciar o processo de clonagem, em razão da necessidade de melhorar a qualidade dos povoamentos a serem implantados. Portanto, o passo inicial para esse objetivo foi definir uma metodologia para resgate de matrizes e enraizamento de estacas da espécie. Como forma de resgatar as matrizes, 24 árvores de um povoamento de candeia com seis anos de idade foram decepadas a 15, 30, 45 e $60 \mathrm{~cm}$ de altura em relação à superfície do solo, sendo que em 12 árvores, procedeu-se ao tratamento de escarificação do solo. A contagem e a coleta de brotos foram executadas aos 65 e 135 dias após a decepa, respectivamente. Das brotações obtidas, foram confeccionados três tipos de estacas: Apical 1, Apical 2 e Basal, que foram tratadas com AIB nas concentrações de $0,200,400,800$ ou $1600 \mathrm{mg} \mathrm{kg}^{-1}$ e colocadas para enraizarem em casa de vegetação climatizada. Com base nos resultados, concluise que a decepa, independente da altura, seguida da escarificação do solo e o enraizamento das estacas preparadas a partir das brotações coletadas de raízes é um método eficiente para resgate de matrizes e enraizamento de estacas de candeia, sendo que os maiores percentuais de enraizamento foram encontrados para as estacas apicais, não variando em função da concentração de AIB.
\end{abstract}

Palavras-chave: Candeia, clonagem, escarificação do solo.

\section{METHODOLOGY FOR STOCK PLANTS RESCUE AND CUTTINGS ROOTING OF Eremanthus erythropappus}

\begin{abstract}
Due to the important ecological function of Eremanthus erythropappus (candeia) wood, combined with the growing demand for its products, studies are being made to develop its silviculture. Among these studies, it is important and strategic to start with the cloning process due to the need for improvement of the stand quality that are to be planted. The initial step toward this goal was to define a methodology for rescue of stock plants and rooting of the species cuttings. As a way to rescue the stock plants, 24 trees aged six years of a candeia stand were severed at 15,30,45 and $60 \mathrm{~cm}$ in height above ground. In 12 trees, it was proceeded soil scarification. The counting and harvesting of sprouts were performed 65 and 135 days after cut, respectively. From the shoots obtained, three types of cuttings were prepared: Top 1, Top 2 and Basal, which were treated with IBA at concentrations of 0, 200, 400, 800 or $1600 \mathrm{mg} \mathrm{kg}^{-1}$ and placed in a greenhouse for rooting. Based on the results, it was conclude that cut, independent of the height, followed by soil scarification and the rooting of cuttings prepared from the shoots collected in the roots, is an effective method for rescue of stock plants and rooting of candeia cuttings and the highest percentage of rooting was found in the Top1 cuttings and did not vary in function of $A I B$ concentration.
\end{abstract}

Key words: Candeia, cloning, soil scarification.

\section{INTRODUÇÃO}

O interesse comercial pela espécie florestal Eremanthus erythropappus (candeia) está na madeira que apresenta alta resistência, durabilidade e poder energético, mas principalmente no óleo extraído de toda a planta, o qual contém alfabisabolol. Esse princípio ativo apresenta propriedades farmacológicas, sendo utilizado na indústria de cosméticos na forma de hidratantes e loções cicatrizantes (PÉREZ, 2001). Para Galdino et al. (2006), a madeira também é utilizada, em sua forma bruta, como mourões para cercas.

Além de ser uma espécie com potencial econômico, a candeia exerce um papel importante no contexto ambiental, formando um maciço florestal (candeal) que se desenvolve em áreas com altitude entre 900 e $1.800 \mathrm{~m}$ (PÉREZ et al., 2004), locais de relevância importância para o abastecimento do lençol freático. Segundo Oliveira Filho

\footnotetext{
${ }^{1}$ Engenheiro Florestal, Professor Doutorando em Engenharia Florestal - Universidade Federal Rural do Rio de Janeiro - Instituto de Florestas - Departamento de Silvicultura - Rod. BR465, Km 47 - 23890-000 - Seropédica, RJ, Brasil - lucas.amaral@ufv.br ${ }^{2}$ Engenheiro Agrônomo, Professor Doutor em Engenharia Florestal - Universidade Federal de Lavras - Departamento de Ciências Florestais - Cx. P. 3037 - 37200-000 - Lavras, MG, Brasil - acdavide@ufla.br

${ }^{3}$ Engenheiro Florestal, Mestrando em Engenharia Florestal - Universidade Federal de Lavras - Departamento de Ciências Florestais Cx. P. 3037 - 37200-000 - Lavras, MG, Brasil - la.florestal@hotmail.com
} 
e Fluminhan Filho (1999), o candeal também funciona como uma espécie de tampão antifogo para outras formações florestais, em razão da resistência a regimes moderados de incêndios.

Uma característica peculiar da espécie é seu desenvolvimento em sítios com solos pouco férteis, rasos e predominantemente em áreas de campos, em altitudes entre 900 e 1800 m (SCOLFORO et al., 2002). Mesmo com essas características ambientais, a candeia consegue se desenvolver nestes ambientes, enquanto outras espécies arbóreas ou mesmo culturas agrícolas apresentam dificuldades de sobrevivência, conforme citado por Pérez (2001) e Scolforo et al. (2008a).

Embora a candeia apresente uma relativa distribuição no estado de Minas Gerais, podendo ser encontrada, principalmente, em áreas montanhosas de diversos municípios, tais como: Aiuruoca, Araxá, Arcos, Belo Horizonte, Capelinha, Carrancas, Caxambu, Delfim Moreira, Guanhães, Itabirito, Juiz de Fora, Madre de Deus, Mariana, Morro do Pilar, Oliveira, Ouro Preto, Viçosa etc. (SCOLFORO et al., 2008b), esta espécie vem sendo ameaçada pelo corte indiscriminado neste Estado, visto que o interesse econômico é grande. Por esse motivo, foram iniciados trabalhos com o intuito de desenvolver sua silvicultura (ABREU, 2008; BRAGA, 2006; ESTOPA et al., 2006; GOULART, 2003; PEREIRA, 1998; PÉREZ, 2001; PÉREZ et al., 2004; REZENDE, 2007; ROSAL, 2004; SCOLFORO et al., 2002; SILVA, 2009; SILVA et al., 2007; SIQUEIRA, 2008; TEIXEIRA et al., 1996; TONETTI et al., 2006; VENTURIN et al., 2005).

Com o início dos trabalhos e maior conhecimento acerca da espécie, proprietários da região Sul de Minas Gerais vêm aproveitando terras antes consideradas improdutivas, para a implantação de pequenos povoamentos de candeia, fato que tem aumentado a demanda por mudas dessa espécie.

A produção de mudas de candeia ainda é efetuada exclusivamente via seminal (SCOLFORO et al., 2008a). Além disso, as sementes são coletadas em povoamentos nativos e os trabalhos têm sido desenvolvidos com materiais genéticos sem nenhum grau de melhoramento, impossibilitando a seleção das melhores progênies, fator preponderante para qualquer manejo racional de uma espécie.

Com a utilização de mudas oriundas de sementes sem nenhum grau de melhoramento, os povoamentos existentes não apresentam o potencial produtivo que poderiam ser alcançados, conforme discutido por Scolforo et al. (2002).

Cerne, Lavras, v. 18, n. 4, p. 631-638, out./dez. 2012
Dessa forma, além da necessidade de obtenção de sementes de melhor qualidade, é necessário iniciar o processo de clonagem da espécie. O estudo da probabilidade de propagação vegetativa é fundamental para a obtenção de ganho máximo em programas de melhoramento que visam à aquisição de genótipos mais produtivos e adaptados a diferentes sítios (ASSIS, 1996). No entanto, resultados inerentes às técnicas de resgate de matrizes e à capacidade de enraizamento de estacas de candeia são ainda incipientes (GOULART, 2003; REZENDE, 2007). Portanto, o objetivo deste estudo foi definir uma metodologia capaz de proceder ao resgate de matrizes e enraizamento de estacas de Eremanthus erythropappus, visando a facilitar a propagação vegetativa de indivíduos adultos da espécie, considerados superiores em trabalhos de melhoramento florestal.

\section{MATERIAL E MÉTODOS}

\subsection{Localização e caracterização da área de estudo}

O estudo foi desenvolvido entre dezembro de 2009 e julho de 2010 no Viveiro Florestal do Departamento de Engenharia Florestal da Universidade Federal de Lavras (UFLA), em Lavras, Minas Gerais.

O clima do município de Lavras é do tipo Cwa, conforme a classificação climática de Köppen. A temperatura média anual está em torno de $19,3^{\circ} \mathrm{C}$, tendo, no mês mais quente e no mês mais frio, temperaturas médias de $22,1^{\circ} \mathrm{e}$ $15,8^{\circ}$, respectivamente. A precipitação anual normal é de $1.530 \mathrm{~mm}$, a evaporação total do ano é igual a $1.343 \mathrm{~mm}$ e a umidade relativa média anual de 76\% (BRASIL, 1992).

\subsection{Material experimental}

Para a realização do estudo foram utilizadas árvores de um povoamento de Eremanthus erythropappus, implantado no Campus da UFLA em janeiro de 2005.

O povoamento é composto por aproximadamente 850 árvores, nas quais foram realizadas medições da circunferência a altura do peito (CAP). Por meio da obtenção dessa variável e seu respectivo desvio padrão, foram selecionadas para serem decepadas, dentre as árvores com valor de CAP acima da média mais uma unidade de desvio padrão $(\mathrm{x} \geq \mu+1,0 \delta), 24$ árvores consideradas superiores.

Em meados de dezembro de 2009 as 24 matrizes selecionadas foram decepadas. No estudo de enraizamento das estacas, foram utilizados os propágulos vegetativos provenientes da brotação de raízes referentes às 24 árvores selecionadas. 


\subsection{Instalação dos Experimentos}

\subsubsection{Resgate das matrizes selecionadas}

Foram testados dois fatores para a obtenção do material vegetativo: 1) alturas de corte $(15,30,45$ e $60 \mathrm{~cm}$ em relação à superfície do solo); 2) exposição, ou não das raízes ao redor da cepa remanescente.

A exposição das raízes, denominada a partir deste momento de escarificação do solo, foi realizada com o auxílio de uma enxada. Para isso, depois de realizada a decepa da árvore, o solo no entorno das cepas foi retirado até uma profundidade variável, capaz de expor a maior área possível de raízes a uma distância de $0,50 \mathrm{~m}$ da cepa em todas as direções, formando um círculo de diâmetro igual a 1,0 m. Durante a escarificação do solo, algumas raízes foram feridas pela lâmina da enxada, porém isto foi considerado como um fator acidental.

Para maior controle experimental, o povoamento foi dividido em três blocos, cada bloco possuindo oito árvores. Dessa forma, o experimento foi montado em um Fatorial 4 (alturas de corte) x 2 (com e sem escarificação do solo), em Blocos Casualizados com três repetições.

\subsubsection{Enraizamento das estacas}

Após 135 dias da decepa, foram coletadas brotações provenientes das raízes, com altura variando de 7 até $20 \mathrm{~cm}$. Das brotações com altura entre 7 e $14 \mathrm{~cm}$, foi confeccionado apenas um tipo de estaca (Apical 1). Das brotações com altura entre 14 e $20 \mathrm{~cm}$, foram confeccionados dois tipos de estaca: uma da parte apical das brotações (Apical 2) e uma da parte basal, contendo um par de folhas (Basal).

As estacas apicais foram preparadas com dois ou mais pares de folhas. Todas foram submetidas ao tratamento com regulador de crescimento ácido-indolbutírico (AIB) nas concentrações: $0,200,400,800$ ou $1600 \mathrm{mg} \mathrm{kg}^{-1}$. Em seguida, foram estaqueadas em tubetes de $55 \mathrm{~cm}^{3}$ e levadas para casa de vegetação climatizada, com controle de temperatura a $29^{\circ} \mathrm{C}$ e umidade relativa do ar acima de $80 \%$. Essas condições foram mantidas enquanto as estacas permaneceram no interior da casa de vegetação.

$\mathrm{O}$ substrato utilizado para estaqueamento e produção das mudas de candeia foi composto de uma mistura de casca de arroz carbonizada, vermiculita de granulometria média e areia, na proporção volumétrica de 4,5:4,5:1, com adição de $4 \mathrm{~kg} \mathrm{~m}^{-3}$ do adubo de liberação controlada Osmocote ${ }^{\circledR}$, na concentração 19:06:10 de NPK.

O experimento foi montado em Fatorial inteiramente ao acaso com 3 (tipos de estacas) x 5 (dosagens de AIB), com três repetições, constituída cada uma de 11 estacas.

\subsection{Avaliações}

\subsubsection{Resgate de matrizes selecionadas}

Após a decepa das matrizes selecionadas e submissão ao tratamento de escarificação do solo, as cepas foram monitoradas regularmente até 135 dias após a montagem do experimento. Esse monitoramento consistiu da eliminação de plantas daninha na área próxima às brotações por meio de capina manual e monitoramento de formigas cortadeiras.

Aos 60 dias após o corte, o número de brotações em cada cepa foi analisado. Foram quantificadas separadamente as brotações obtidas da cepa remanescente e as obtidas do sistema radicular exposto. A partir dos dados obtidos, foi realizada a análise de variância com auxílio do Programa Estatístico SisVar (FERREIRA, 2000), segundo metodologia proposta por Banzato e Kronka (2006).

Aos 135 dias da montagem do experimento, todas as brotações existentes foram retiradas. Em seguida, a área ao redor de cada cepa foi limpa com o intuito de possibilitar maior contraste das raízes expostas naturalmente ou pela escarificação.

Depois de limpa e com auxílio de uma lona plástica com orifício circular de raio igual a $0,50 \mathrm{~m}$, a área correspondente a $0,79 \mathrm{~m}^{2}$ foi fotografada.

As fotografias digitais foram processadas no software de edição de imagens Adobe Photoshop CS3 ${ }^{\circledR}$. Após a obtenção das imagens, as mesmas passaram por um processo de vetorização manual. A análise das imagens digitais consistiu no reconhecimento da cena para a geração de características dimensionais por meio do método de contagem de seus elementos formadores (pixels) (TEIXEIRA et al., 2006).

A estimativa da área de raízes expostas foi obtida pela razão entre o número de pixels de raízes e o número de pixels do gabarito.

\subsubsection{Enraizamento das estacas}

As estacas permaneceram na casa de vegetação climatizada por 28 dias. Ao serem retiradas, foram levadas para a casa de sombra e, aos 43 dias, levadas para a área a pleno sol.

Ao longo do período de produção das mudas clonais de candeia, foram realizadas avaliações quanto aos percentuais de estacas com raízes acima de $10 \mathrm{~cm}$ de comprimento (raízes emitidas da base do tubete) e de sobrevivência das estacas na saída da casa de vegetação, assim como percentuais de estacas com raízes acima de $10 \mathrm{~cm}$ e de sobrevivência das estacas na saída da casa de sombra. Aos 65 dias de idade, avaliou-se o percentual de sobrevivência das mudas obtidas.

Cerne, Lavras, v. 18, n. 4, p. 631-638, out./dez. 2012 
A partir dos dados obtidos para as características avaliadas, foram realizadas as análises de variância de acordo com as mesmas metodologias descritas anteriormente.

\section{RESULTADOS E DISCUSSÃO}

\subsection{Resgate de matrizes selecionadas}

Os primeiros sinais da ocorrência de brotações foram observados aos 25 dias após o corte das matrizes, por meio da diferenciação de gemas crescendo sobre a superfície das raízes expostas (Figura 1A). Novas brotações surgiram até 50 dias.

Desde o início do aparecimento de brotações, observou-se que a maioria dos brotos se originava a partir das raízes que haviam sido expostas por meio do tratamento de escarificação (Figura 1B). No entanto, brotações também surgiram ao longo da cepa remanescente (Figura 1C), porém em número menor.

Com base na análise estatística, verificou-se que houve diferença significativa apenas para o fator escarificação do solo (Tabela 1).

Ao analisar o número de brotações obtidas das matrizes que foram submetidas à técnica tradicional de resgate (decepa), foi possível conseguir em média 25 brotações por matriz, totalizando 300 brotações, dentre as quais, 192 se originaram de raízes naturalmente expostas e 108 ao longo das cepas remanescentes (Tabela 2). Com relação às raízes naturalmente expostas, Rezende (2007) observou que a maioria das brotações obtidas após o corte das árvores de um candeal nativo no município de Aiuruoca, sul de Minas Gerais, era originada de raízes, que naturalmente se encontravam expostas pelo fato de o solo ser, naquele sítio, mais raso.

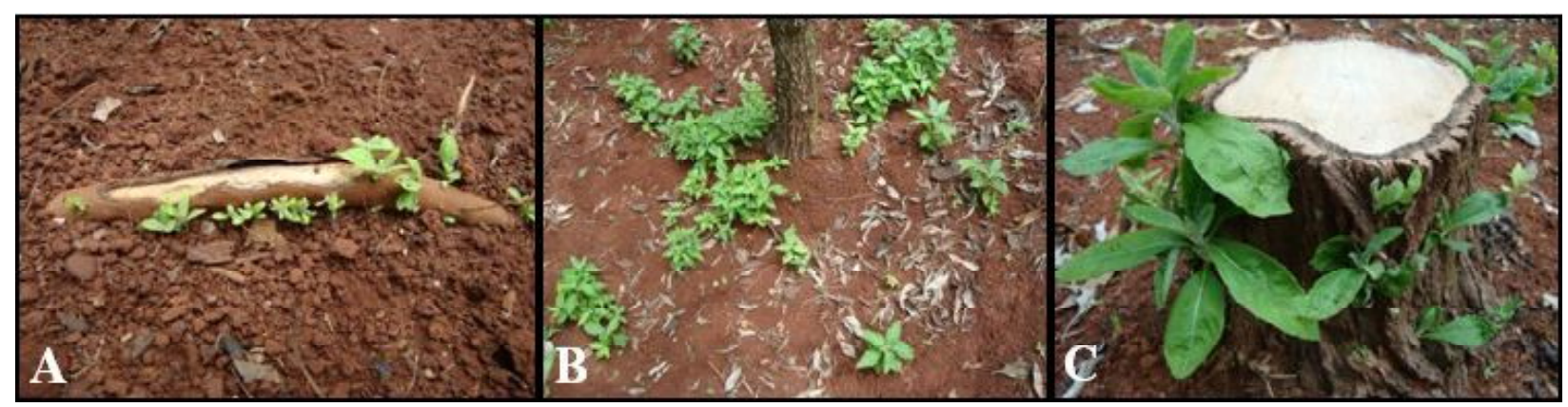

Figura 1 - A) brotações aos 25 dias após a decepa das matrizes; B) brotações de raízes expostas por meio do tratamento de escarificação; C) brotações ao longo da cepa remanescente, em plantas de candeia.

Figure 1 - A) shoots at 25 days after cutting the stock plants; B) Root shoot exposed by scarification; C) Shoots along the remaining stump, in candeia plants.

Tabela 1 - Resultados da ANAVA referente ao número de brotações em matrizes de candeia, 60 dias após a decepa.

Table 1 - Results of ANOVA of the number of shoots in candeia stock plants at 60 days after cut.

\begin{tabular}{|c|c|c|c|c|}
\hline \multirow{2}{*}{$\begin{array}{l}\text { Fontes de } \\
\text { Variação }\end{array}$} & \multirow{2}{*}{$\begin{array}{l}\text { Graus de } \\
\text { Liberdade }\end{array}$} & \multicolumn{3}{|c|}{ Quadrados Médios } \\
\hline & & $\begin{array}{c}\text { Número de Brotações de } \\
\text { Raiz }\end{array}$ & $\begin{array}{c}\text { Número de Brotações de } \\
\text { Toco }\end{array}$ & Número total de Brotações \\
\hline Bloco & 2 & $13,0756^{\mathrm{ns}}$ & $12,9651^{\mathrm{ns}}$ & $32,1237^{\mathrm{ns}}$ \\
\hline Escarificação & 1 & $418,6413 *$ & $0,3515^{\mathrm{ns}}$ & $343,4136 *$ \\
\hline Altura & 3 & $12,7322^{\mathrm{ns}}$ & $3,8260^{\mathrm{ns}}$ & $15,8447^{\mathrm{ns}}$ \\
\hline Esc. x Alt. & 3 & $4,0975^{\mathrm{ns}}$ & $7,1942^{\mathrm{ns}}$ & $5,4590^{\mathrm{ns}}$ \\
\hline Resíduo & 14 & 12,9263 & 3,8455 & 12,5597 \\
\hline Total & 23 & & & \\
\hline
\end{tabular}

Cerne, Lavras, v. 18, n. 4, p. 631-638, out./dez. 2012 
Tabela 2 - Número médio de brotações por matriz, em função da origem das brotações e dos tratamentos testados, em plantas de candeia.

Table 2 - Average number of shoots per stock plants, in function of the origin of the shoots and the treatments, in candeia plants.

\begin{tabular}{|c|c|c|c|}
\hline \multirow{2}{*}{ Tratamento } & \multicolumn{2}{|c|}{ Origem das Brotações } & \multirow{2}{*}{ Total de brotações } \\
\hline & Brotações de raiz & Brotações do toco & \\
\hline Sem escarificação do solo & $16 \mathrm{a}$ & $9 \mathrm{a}$ & $25 \mathrm{a}$ \\
\hline Com escarificação do solo & $140 \mathrm{~b}$ & $7 \mathrm{a}$ & $147 \mathrm{~b}$ \\
\hline
\end{tabular}

Letras iguais na coluna, não diferem estatisticamente pelo Teste Tukey, a 5\% de probabilidade.

Quando avaliadas as matrizes submetidas à decepa e escarificação do solo, foram obtidas, em média, 147 brotações por matriz, num total de 1764 brotações (1680 originadas de raízes expostas pela escarificação e 84 ao longo das cepas), evidenciando que a decepa aliada à escarificação é uma técnica eficiente de resgate em matrizes selecionadas de árvores de candeia.

Outras espécies apresentam capacidade de regeneração a partir da brotação de raízes. Neves e Carpanezzi (2009) comentam que o nim (Azadirachta indica) regenera-se tanto por sementes, como por brotações de raízes. Ferreira (2008) e Lima (2007) salientam que o bacurizeiro (Platonia insignis) apresenta uma notável capacidade de regeneração natural por brotações oriundas de raízes de plantas adultas, mesmo após o corte da plantamãe, possibilitando o manejo de povoamentos clonais.

Conforme os resultados encontrados, poderia sugerir que a escarificação do solo para a exposição das raízes teria sido suficiente para induzir brotações nas matrizes selecionadas, sem a necessidade de decepa. No entanto, isto não ocorre, uma vez que as matrizes com raízes expostas naturalmente só apresentaram brotações após a sua decepa.

Utilizando-se da escarificação do solo, não foi possível conseguir a mesma área de raízes expostas em todas as matrizes, pelo fato de cada planta apresentar, naturalmente, uma distribuição do seu sistema radicular. Contudo, sempre que possível, deve-se buscar expor ao máximo as raízes das plantas selecionadas, pois quanto maior a área de exposição, maior será o número de brotos emitidos (Figura 2).

Além da utilização da técnica de escarificação para a obtenção de propágulos para o processo de resgate de matrizes selecionadas, essa técnica poderia ser utilizada em planos de manejo de candeais nativos com o propósito de conduzir o povoamento por meio da talhadia, conforme estudado em Platonia insignis (FERREIRA, 2008).
A maioria dos planos de manejo existentes para a espécie Eremantus erythropappus tem sido implementada por meio da utilização do sistema de árvores porta-sementes. Segundo Scolforo et al. (2008a), o sistema baseia-se no corte das árvores e condução da regeneração a partir de sementes advindas de árvores remanescentes.

No sistema de árvores porta-sementes adotado para a candeia, é realizada a escarificação do solo a fim de facilitar a germinação das sementes e sobrevivência das plântulas (SCOLFORO et al., 2008a), facilitando concomitantemente, a brotação das cepas a partir das raízes expostas. Atualmente, toda regeneração é considerada como obtida da germinação de sementes, sem levar em consideração o potencial que a espécie apresenta de brotação de suas raízes.

\subsection{Enraizamento de estacas}

O primeiro sinal de enraizamento das estacas foi observado a partir do $20^{\circ}$ dia, por meio da constatação da formação de raízes, as quais já podiam ser vistas no fundo de alguns tubetes.

Com base na análise dos dados, verificou-se que apenas o tipo de estaca interferiu significativamente em todas as características avaliadas (Tabela 3), sendo que as estacas confeccionadas a partir da parte basal das brotações apresentaram os menores percentuais de enraizamento e, consequentemente de sobrevivência.

Pelos resultados obtidos desse parâmetro, notase que estacas apicais de candeia formam um sistema radicular mais rapidamente do que estacas retiradas da base das brotações. Aos 43 dias após o estaqueamento, aproximadamente $36 \%$ das estacas apicais já apresentavam raízes emitidas da base inferior do tubete, enquanto nas estacas basais, este valor era inferior a $1,0 \%$.

Cerne, Lavras, v. 18, n. 4, p. 631-638, out./dez. 2012 


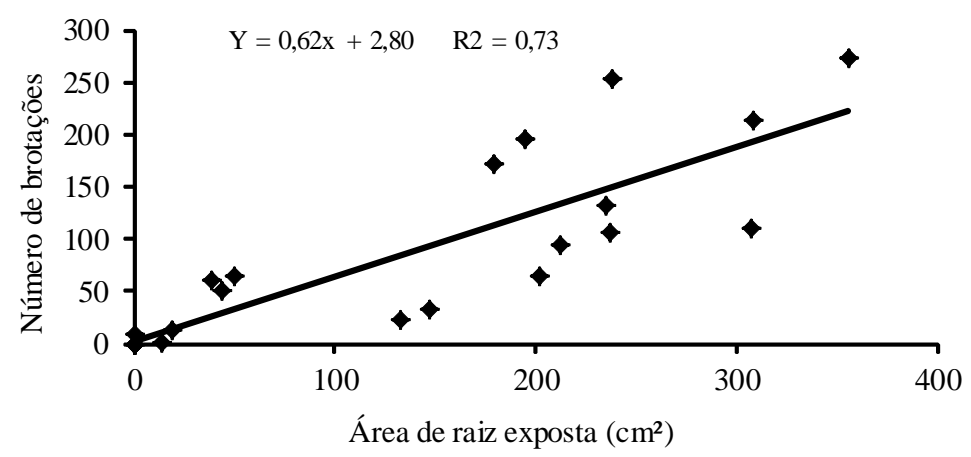

Figura 2 - Número de brotações originadas de raízes de plantas de candeia, em função da área de raiz exposta.

Figure 2 - Number of shoots originated from roots of candeia plants, in function of the exposed root area.

Tabela 3 - Valores médios para enraizamento e sobrevivência de estacas de candeia, em função do tipo de estaca confeccionada.

Table 3 - Mean values for rooting and survival of candeia cuttings, in function of the cutting types.

\begin{tabular}{|c|c|c|c|c|c|}
\hline \multirow{2}{*}{ Tipo de Estaca } & \multicolumn{5}{|c|}{ Características avaliadas } \\
\hline & PECV10 (\%) & $\operatorname{PSCV}(\%)$ & PECS10 $(\%)$ & $\operatorname{PSCS}(\%)$ & PS65 (\%) \\
\hline Basal & $0,61 \quad \mathrm{a}$ & 89,09 a & 0,61 a & 76,97 a & 69,70 a \\
\hline Apical 1 & $18,79 \mathrm{~b}$ & $100,00 \mathrm{~b}$ & $35,15 \mathrm{~b}$ & $98,79 \quad b$ & $98,18 \quad b$ \\
\hline Apical 2 & $23,03 \mathrm{~b}$ & $99,39 \mathrm{~b}$ & $38,18 \quad b$ & $99,39 \quad b$ & $98,79 \mathrm{~b}$ \\
\hline
\end{tabular}

PECV10: percentual de estacas com raízes maiores que $10 \mathrm{~cm}$ na saída da casa de vegetação; PSCV: percentual de sobrevivência das estacas na saída da casa de vegetação; PECS10: percentual de estacas com raízes maiores que $10 \mathrm{~cm}$ na saída da casa de sombra; PSCS: percentual de sobrevivência das estacas na saída da casa de sombra; PS65: percentual de sobrevivência de mudas aos 65 dias de idade. Letras iguais na coluna, não diferem estatisticamente pelo Teste Tukey, a 5\% de probabilidade.

Resultados semelhantes são encontrados em Alfenas et al. (2004) e Xavier et al. (2009), os quais relatam que em eucalipto, estacas apicais, contendo dois pares de folhas enraízam melhor e mais precocemente que estacas basais com um par de folhas. Segundo os mesmos autores, isto ocorre em razão das folhas, especialmente as mais novas e as gemas, constituírem fontes de carboidratos, reguladores de crescimento e outros compostos essenciais para a rizogênese.

Os dois tipos de estacas que foram confeccionados a partir da parte apical das brotações apresentaram, em média, 98\% de sobrevivência aos 65 dias após o estaqueamento, valor superior ao encontrado para estacas do tipo Basal que apresentaram em média 70\% de sobrevivência. Além disso, o percentual de sobrevivência encontrado para as estacas do tipo Apical é semelhante aos maiores valores percentuais de sobrevivência encontrados para clones comerciais de eucalipto no Brasil (FERREIRA et al., 2004; MELO et al., 2011; TITON et al., 2003).

Cerne, Lavras, v. 18, n. 4, p. 631-638, out./dez. 2012
Durante o período compreendido entre a saída das estacas da casa de vegetação e a avaliação aos 65 dias após o estaqueamento, a sobrevivência das estacas basais caiu de 89\% para aproximadamente $70 \%$. Assim, como concluído por Ferreira et al. (2004) e Melo et al. (2011) ao estudarem o enraizamento de diferentes clones de eucalipto, isto pode ser um indício de que para o completo enraizamento de estacas basais de candeia, seja necessária a permanência das estacas na casa de vegetação por tempo superior aos 28 dias.

Mesmo com percentuais de sobrevivência significativamente inferiores aos obtidos pelas estacas apicais, a preparação e estaqueamento de estacas basais de candeia é uma alternativa atraente para a clonagem da espécie, principalmente quando o objetivo é o resgate de material selecionado.

\section{CONCLUSÕES}

A decepa, independente da altura, seguida da escarificação do solo no entorno da cepa contribui para a 
produção de brotações, mostrando ser uma técnica eficiente para o resgate de matrizes selecionadas de Eremanthus erythropappus.

As estacas de candeia confeccionadas a partir das brotações produzidas pelo método de resgate supracitado, quando estaqueadas em casa de vegetação climatizada, apresentaram um elevado percentual de enraizamento, independente da utilização de AIB, mesmo no caso de estacas basais.

Para facilitar a propagação vegetativa de indivíduos adultos da espécie Eremanthus erythropappus, sugerese proceder à decepa das plantas, seguida da escarificação do solo e estaqueamento dos propágulos confeccionados a partir das brotações produzidas após a decepa.

\section{AGRADECIMENTOS}

À FAPEMIG pela concessão da bolsa e ao Departamento de Engenharia Florestal da UFLA pela disponibilização de toda a infraestrutura necessária.

\section{REFERÊNCIAS}

ABREU, G. B. Influência do esterco bovino na produção de mudas de Eremanthus erythropappus (candeia). 2008. 33 f. Monografia (Graduação em Agronomia) - Universidade Federal de Lavras, Lavras, 2008.

ALFENAS, A. C. et al. Clonagem e doenças do eucalipto. Viçosa, MG: UFV, 2004. 442 p.

ASSIS, T. F. Melhoramento genético do eucalipto. Informe Agropecuário, Belo Horizonte, v. 18, n. 185, p. 32-51, 1996.

BANZATO, D. A.; KRONKA, S. N. Experimentação agrícola. 4. ed. Jaboticabal: FUNEP, 2006. 237 p.

BRAGA, E. A. Substratos e fertilização na produção de mudas de candeia (Eremanthus erythropappus) (DC.) MacLeisch. em tubetes. 2006. 88 f. Dissertação (Mestrado em Engenharia Florestal) - Universidade Federal de Lavras, Lavras, 2006.

BRASIL. Ministério da Agricultura e Reforma Agrária. Normais climatológicas 1961-1990. Brasília, 1992. 84 p.

ESTOPA, R. A. et al. Diversidade genética em populações naturais de candeia (Eremanthus erythropappus (DC.) MacLeish). Scientia Forestalis, Piracicaba, v. 1, n. 70, p. 97106, jan./abr. 2006.
FERREIRA, D. F. Análises estatísticas por meio do SisVar para Windows versão 4.0. In: REUNIÃO ANUAL DA REGIÃO BRASILEIRA DA SOCIEDADE INTERNACIONAL DE BIOMETRIA, 45., 2000, São Carlos. Anais... São Carlos: UFSCAR, 2000. p. 255-258.

FERREIRA, E. M. et al. Determinação do tempo ótimo do enraizamento de miniestacas de clones de Eucalyptus spp. Revista Árvore, Viçosa, v. 28, n. 2, p. 183-187, mar./abr. 2004.

FERREIRA, M. S. G. Manejo da espécie Platonia insignis Mart - Bacurizeiro, em florestas secundárias da Amazônia Oriental: proposta para uma produção sustentável. 2008. 246 f. Tese (Doutorado em Desenvolvimento Sustentável) - Universidade de Brasília, Brasília, 2008.

GALDINO, A. P. P. et al. Estudo sobre o rendimento e qualidade do óleo de candeia (Eremanthus ssp) e a diferença das diferentes origens comerciais de sua madeira. Revista Brasileira de Plantas Medicinais, Botucatu, v. 8, n. 4, p. 44-46, out./dez. 2006.

GOULART, P. B. Desenvolvimento de metodologia para enraizamento de estacas de candeia (Eremanthus erythropappus) (DC.) MacLeisch. 2003. 32 f. Monografia (Graduação em Engenharia Florestal) - Universidade Federal de Lavras, Lavras, 2003.

LIMA, M. C. Bacuri: (Platonia insignis Mart.-Clusiaceae), agrobiodiversidade. São Luís: Instituto Interamericano de Cooperação para a Agricultura, 2007. 210 p.

MELO, L. A. et al. Otimização do tempo de enraizamento de miniestacas de clones híbridos de Eucalyptus grandis. Revista Árvore, Viçosa, v. 2, n. 4, p. 759-767, jul./ago. 2011.

NEVES, E. J. M.; CARPANEZZI, A. A. Prospecção do cultivo do nim (Azadirachta indica) no Brasil. Colombo: EMBRAPA Florestas, 2009. 34 p.

OLIVEIRA FILHO, A. T.; FLUMINHAN FILHO, M. Ecologia da vegetação do parque florestal Quedas do Rio Bonito. Cerne, Lavras, v. 5, n. 2, p. 51-64, jul./dez. 1999.

PEREIRA, A. A. S. Nutrição e adubação de candeia. 1998. 22 f. Monografia (Graduação em Engenharia Florestal) Universidade Federal de Lavras, Lavras, 1998.

Cerne, Lavras, v. 18, n. 4, p. 631-638, out./dez. 2012 
PÉREZ, J. F. M. Sistema de manejo para a candeia (Eremanthus erythropappus (DC.) MacLeish). 2001. 71 f. Dissertação (Mestrado em Engenharia Florestal) Universidade Federal de Lavras, Lavras, 2001.

PÉREZ, J. F. M. et al. Sistema de manejo para a candeia Eremanthus erythropappus (DC.) Macleish, a opção do sistema de corte seletivo. Cerne, Lavras, v. 10, n. 2, p. 257273, jul./dez. 2004.

REZENDE, A. A. Enraizamento de estacas de candeia (Eremanthus erythropappus (DC.) MacLeish). 2007. 85 f. Dissertação (Mestrado em Engenharia Florestal) Universidade Federal de Lavras, Lavras, 2007.

ROSAL, L. F. Germinação, indução de calos, micropropagação e anatomia foliar da candeia (Eremanthus erythropappus (DC.) MacLeish). 2004. $106 \mathrm{f}$. Dissertação (Mestrado em Fitotecnia) - Universidade Federal de Lavras, Lavras, 2004.

SCOLFORO, J. R. S. et al. O manejo da candeia nativa. Lavras: UFLA, 2008a. 44 p.

SCOLFORO, J. R. S. et al. O manejo de plantações de candeia. Lavras: UFLA, 2008b. 26 p.

SCOLFORO, J. R. S. et al. Manejo sustentável da candeia Eremanthus erythropappus e Eremanthus incanus: relatório técnico científico. Lavras: UFLA, 2002. 350 p.

SILVA, A. C. et al. Variações genéticas na qualidade do sistema radicular de mudas de candeia (Eremanthus erythropappus (DC.) MacLeish). Revista Árvore, Viçosa, v. 31, n. 4, p. 609617, jul./ago. 2007.

SILVA, C. P. C. Crescimento e produção da candeia em plantio sujeito a diferentes espaçamentos e podas. 2009.
131 f. Dissertação (Mestrado em Engenharia Florestal) Universidade Federal de Lavras, Lavras, 2009.

SIQUEIRA, F. F. Efeito de substratos contendo diferentes adubações na semeadura direta de candeia (Eremanthus erythropappus). 2008. 54 f. Monografia (Graduação em Engenharia Agronômica) - Escola Agrotécnica Federal de Inconfidentes, Inconfidentes, 2008.

TEIXEIRA, E. F.; CICERO, S. M.; DOURADO NETO, D. Análise de imagens digitais de plântulas para avaliação do vigor de sementes de milho. Revista Brasileira de Sementes, Londrina, v. 28, n. 2, p. 159-167, maio/ago. 2006.

TEIXEIRA, M. C. B. et al. Influência da luz na germinação de sementes de candeia (Vanillosmopsis erythropappa Schult. Bip). In: ENCONTRO REGIONAL DE BOTÂNICA, 28., 1996, Belo Horizonte. Anais... Belo Horizonte: SBB; PUCMG, 1996. p. 35-41.

TITON, M. et al. Eficiência das minicepas e microcepas na produção de propágulos de clones de Eucalyptus grandis. Revista Árvore, Viçosa, v. 27, n. 5, p. 619-625, set./out. 2003.

TONETTI, O. A. O.; DAVIDE, A. C.; SILVA, E. A. A. Qualidade física e fisiológica de sementes de Eremanthus erythropappus (DC.) Macleish. Revista Brasileira de Sementes, Londrina, v. 28, n. 1, p. 114-121, jan./abr. 2006.

VENTURIN, N. et al. Adubação mineral da candeia (Eremanthus erythropappus (DC.) McLeish). Floresta, Curitiba, v. 35, n. 2, p. 211-219, maio/ago. 2005.

XAVIER, A.; WENDLING, I.; SILVA, R. L. Silvicultura clonal: princípios e técnicas. Viçosa, MG: UFV, 2009. 272 p. 